OPEN ACCESS

Edited by:

Fang Pan,

Shandong University, China

Reviewed by:

Zhibin Wang,

Johns Hopkins University,

United States

Shin-ichi Horike,

Kanazawa University, Japan

*Correspondence:

Tomoko Soga

tomoko.soga@monash.edu

Specialty section:

This article was submitted to

Epigenomics and Epigenetics,

a section of the journal

Frontiers in Genetics

Received: 01 September 2020 Accepted: 14 December 2020

Published: 22 January 2021

Citation:

Soga T, Teo CH and Parhar I (2021) Genetic and Epigenetic Consequence of Early-Life Social Stress on

Depression: Role of

Serotonin-Associated Genes.

Front. Genet. 11:601868.

doi: 10.3389/fgene.2020.601868

\section{Genetic and Epigenetic Consequence of Early-Life Social Stress on Depression: Role of Serotonin-Associated Genes}

\author{
Tomoko Soga*, Chuin Hau Teo and Ishwar Parhar \\ Brain Research Institute, Jeffrey Cheah School of Medicine and Health Sciences, Monash University Malaysia, Bandar \\ Sunway, Malaysia
}

Early-life adversity caused by poor social bonding and deprived maternal care is known to affect mental wellbeing and physical health. It is a form of chronic social stress that persists because of a negative environment, and the consequences are long-lasting on mental health. The presence of social stress during early life can have an epigenetic effect on the body, possibly resulting in many complex mental disorders, including depression in later life. Here, we review the evidence for early-life social stress-induced epigenetic changes that modulate juvenile and adult social behavior (depression and anxiety). This review has a particular emphasis on the interaction between early-life social stress and genetic variation of serotonin associate genes including the serotonin transporter gene (5-HTT; also known as SLC6A4), which are key molecules involved in depression.

Keywords: serotonin, depression, social stress, epigenetic modification, 5-HT receptor

\section{INTRODUCTION}

History of early-life social stress indicates adverse effects on functions of the hypothalamicpituitary-adrenal axis and stress response in later life (Denhardt, 2018; Lapp et al., 2019) linked to the development of the major depressive disorder in adolescents and adults (Hettema et al., 2006; Pace et al., 2006; Rao et al., 2008; Heim and Binder, 2012; Bunea et al., 2017). These clinical findings are backed by animal studies demonstrating that poor social bonding and reduced maternal care can subsequently cause altered behavior and heightened anxiety, as well as negative consequences on the brain development of offsprings (Eiland and McEwen, 2012; Carini and Nephew, 2013; Murgatroyd et al., 2015).

The effect of early-life social stress on the genetics of depression can be described as the influence of the environment on the genes of the brain - in other words, epigenetics. Epigenetics involves modifications to gene expression that may be inherited by the offspring, without any changes in the DNA sequences that encodes for those genes (Hochberg et al., 2011). Epigenetic modifications involve three processes, DNA methylation, histone modification, and various RNA-mediated processes. In DNA methylation, a methyl group is transferred to C-5 of a cytosine residue in DNA - this interferes with the ability of transcription factors to bind to DNA, and as such, high methylation levels are associated with repression of gene expression (Crabtree, 2020). Histone modification, on the other hand, involves either methylation, acetylation, or phosphorylation of amino acids in the 
histone protein tails; as the histones control how tightly chromatin is coiled and a tightly packed chromatin restricts access of regulatory factors to DNA, modification of those histones can control how much genes are expressed (Crabtree, 2020). Finally, non-coding RNAs can facilitate chromatin modifications, while microRNAs can pair to complementary target mRNAs, directly suppressing translation from mRNA to protein (Crabtree, 2020).

It is well known that early-life social stress leads to persistent epigenetic modifications of target genes associated with changes in emotional behavior (Nugent et al., 2011; McCann et al., 2017; Fogelman and Canli, 2019). There has been a growing body of work in the past decade, documenting epigenetic action in the brain, stemming from exposure to early-life social stress in animal models and human studies (Murgatroyd et al., 2009; McClelland et al., 2011; Heim and Binder, 2012; Huang, 2014; Provençal and Binder, 2015; Vaiserman, 2015). These studies have indicated various lasting changes in gene expression due to early-life stress, such as altered arginine vasopressin expression (Murgatroyd et al., 2009) and increases in seizure and epilepsy incidences (Huang, 2014). Prenatal stress caused elevated methylation of a glucocorticoid receptor gene in infants, altering their reactivity to stress (Oberlander et al., 2008). A genome-wide study discovered significant methylation differences within promoters of subjects exposed to early-life stress; 248 promoters showed hypermethylation, while 114 showed hypomethylation. The expressions of genes involved in neuronal plasticity, in particular, were significantly different (Labonté et al., 2012). Genes undergoing methylation in association with early-life social stress-induced depression are also well studied (Schoenherr and Anderson, 1995; Jiang et al., 2019). The monoaminergic theory is supported as the main neuropathogenesis of depression. Based on this, epigenetic modifications of monoamine-related genes such as transporters, metabolic enzymes, synthesis enzymes, and receptors have been well investigated to understand the neuropathogenesis of depression.

Serotonin (5-hydroxytryptamine, 5-HT) is the main monoamine system involved in the neuropathogenesis of depression. The key 5-HT-related genes are serotonin transporter (5-HTT; also known as SLC6A4), monoamine oxidase A (MAO-A), tryptophan hydroxylase 2 (TPH2), and 5-HT receptors. These 5-HT-related genes and their signaling pathways are involved in brain development, stress response, and emotional control. Epigenetic alterations of 5-HT-related genes may be the underlying effect of early life stress on depression (Parade et al., 2017). Since depression is closely tied to the 5-HT system, therefore, the examination of epigenetic influence on 5-HT-associated genes could generate an interesting body of work that would serve better to explain the interplay between nature and nurture in depression. In this review, we looked at the mounting evidence for early life social stress-induced epigenetic changes in several 5-HT-associated genes and how these gene modifications influence behavior in later life. Besides, treatments that reduce early-life social stress are also reviewed to understand their impact on the attenuation of genetic and behavioral changes.

\section{EARLY LIFE SOCIAL STRESS-INDUCED EPIGENETIC CHANGES IN SEROTONIN-RELATED GENES}

\section{Serotonin Transporter}

The 5-HTT gene was first sequenced and characterized by Lesch et al. (1994), but its function in terminating serotonergic neurotransmission was already documented earlier (Kanner and Schuldiner, 1987). Variants of 5-HTT gene potentially increase susceptibility to a stressful environment, increasing the risk for mental disorders. There have been numerous studies and reviews covering the role of 5-HTT in psychiatric disorders, indicating that polymorphisms in the 5-HTT lead to serotonergic dysfunction that can develop into various diseases such as major depressive disorder and bipolar disorder (Mann et al., 2000; Zanardi et al., 2000; Hahn and Blakely, 2002; Anguelova et al., 2003; Murphy et al., 2004; Abdolmaleky et al., 2014). An epidemiology study performed on a cohort of 1,037 children identified a correlation between the presence of a functional polymorphism in the 5-HTT gene in individuals having a heterozygous or homozygous variant of the short allele, who exhibited greater susceptibility to life stress history for predicting depression, compared to individuals with a homozygous long allele variant (Caspi et al., 2003).

The influence of epigenetics on 5-HTT is also well documented. For example, DNA hypermethylation, an indicator of epigenetic influence, has been observed in the 5-HTT gene of schizophrenic patients alongside reduced 5-HTT expression (Abdolmaleky et al., 2014). Increased methylation in the proximal promoter region of 5-HTT is an epigenetic change that has a positive correlation with increased responsiveness to threat in the amygdala (Nikolova et al., 2014).

As stress is one of the major drivers for epigenetic changes in the brain (Gudsnuk and Champagne, 2012), it stands to reason that early life social stress would also have a major effect on epigenetic modifications to the 5-HTT gene. Methylation of retro-transposonal AluJb element is associated with stress response under major depressive disorder, where lower methylation has a better stress-adaptive reaction (Schneider et al., 2018). The link between methylation and depression is influenced by genetic variation - specific genotypes have higher methylation associated with depression, while those homozygous for short 5-HTT alleles exhibit lower methylation in association with depression (Lam et al., 2018). DNA methylation of 5-HTT in the 10-year-old twins experiencing discordant stress through bullying has been demonstrated to be significantly higher compared to their co-twin that did not undergo bullying in the same period (Ouellet-Morin et al., 2013). The focus on twins indicates that childhood bullying - early life social stress - is the influencer for increased 5-HTT methylation rather than predetermined genetic factors. The bullied twin also exhibited blunted cortisol responses in comparison to the non-bullied twin (Ouellet-Morin et al., 2013).

Research using animal models supports the role of stress during early life - it causes epigenetic changes that may be associated with risk of depression. Peer rearing in rhesus 
macaques, which is a form of early life stress in comparison to maternal rearing (Harlow and Suomi, 1974; Suomi et al., 1976), causes reduced H3K4me3 (Histone 3 protein with trimethylation at lysine 4) binding at the promoter of the 5-HTT gene (Lindell et al., 2012). As H3K4me3 is an epigenetic modification that promotes gene expression, lower H3K4me3 indicates lower 5-HTT expression. This is further supported by the finding of serotonin metabolite 5-HIAA in the cerebrospinal fluid of peer-reared macaques, which suggests a decreased serotonergic function in the central nervous system (Lindell et al., 2012).

Homozygous and heterozygous 5-HTT knockout rats when exposed to early-life stress show decreased serotonergic innervation to Edinger-Westphal urocortin 1 neurons (van der Doelen et al., 2017). Abnormal levels of urocortin 1 have been associated with major depressive disorder (Ryabinin et al., 2012; Waters et al., 2015), suggesting that early-life stress can interact with 5-HTT to cause depressive-like neurophysiology. Furthermore, heterozygous 5-HTT knockout rats exposed to early life social stress triggered by maternal separation, exhibit anhedonic behavior in the form of lower sucrose preference (Houwing et al., 2019). The same study also found low gene expression of nerve growth factor. Examination of clinical studies has reported a significant correlation between reduced nerve growth factor expression and the diagnosis of major depressive disorder (Chen et al., 2015). As a whole, these studies provide strong support for the role of epigenetic action on 5-HTT in early life social stress.

\section{Monoamine Oxidase A}

MAOA is involved in breaking down serotonin. An increase in MAOA expression results in a decrease in serotonin levels in the brain, which has been suggested as the main factor in major depressive disorder (Naoi et al., 2018). Epigenetic regulation of MAOA has been documented in humans (Shumay et al., 2012). In particular, methylation of MAOA in the promoter region of CpG5 and CpG11 increases MAOA expression, which in turn decreases serotonin levels; this has been observed in female patients with depression (Domschke et al., 2015). Behavioral disinhibition in children has been associated with a functional promoter polymorphism on MAOA (MAOA-LPR) that interacts with early life social stress (Enoch et al., 2010). Furthermore, while early life social stress has been associated with increased aggressive disorders in males through the MAOA-L allele, such stress exposes $M A O A-L$ females to a higher risk of developing depression (Melas et al., 2013). It has been suggested that the susceptibility of MAOA- $L$ females to depression may be a result of epigenetic dysregulation of MAOA by early life stressors, which affects DNA methylation of the glucocorticoid receptor gene NR3C1 (Melas et al., 2013).

Studies in rodents have also drawn similar connections between early life stress and epigenetic control of MAOA. Early life social stress induces $\mathrm{CpG}$-specific methylation in the MAOA promoter, which elevates MAOA expression in the dorsal striatum - this is associated with voluntary alcohol consumption (Bendre et al., 2019). The effect of peripubertal stress on the epigenetic state of $M A O A$ is associated with the development of antisocial behavior (Márquez et al., 2013). The development of aggressive behavior is sexually dimorphic, with MAOA hypermethylation in the hypothalamus and in the prefrontal cortex of male rats. In contrast, female rats do not exhibit any changes in epigenetic control of MAOA (Konar et al., 2019).

\section{Tryptophan Hydroxylase 2}

The gene for tryptophan hydroxylase 2 (TPH2) is a neuronspecific rate-limiting 5 -HT biosynthetic enzyme in the brain. Alterations in TPH2 gene expression is involved in the pathogenesis and treatment of MDD (Tsai et al., 2009; Xu et al., 2012). Single-nucleotide polymorphisms (SNPs) in TPH2 gene are linked to 5-HT dysfunction (Gao et al., 2012), which have been associated with MDD (Zill et al., 2004; Zhang et al., 2005), and one of the SNPs in the TPH2 gene is associated with amygdala and hippocampal volume (Inoue et al., 2010). The promoter region of the TPH2 gene lacks a CpG island; however, there are numerous scattered $\mathrm{CpG}$ sites and an enriched signal of DNA hypomethylation at the 5'-UTR locus (Chen and Miller, 2012). A recent study has shown that hypermethylation of the CpG-site in the TPH2 gene during early-life stress could reduce antidepressant response within the first 2 weeks of treatment in patients with MDD (Xu et al., 2016; Shen et al., 2020). Furthermore, methylation of a single $\mathrm{CpG}$ site in the promoter region of TPH2 significantly decreases TPH2 gene expression levels. This methylation is also partially linked with suicide in MDD patients (Zhang et al., 2015). These studies suggest the impact of early life social stress-associated epigenetic action on TPH2 gene and depression.

\section{5-HT Receptors}

Seven families of 5-HT receptors and their subtypes have been identified, namely, 5-HTI (5-HT1A, 5-HT1B, 5-HTID, 5-HTIE, and 5-HT1F), 5-HT2 (5-HT2A, 5-HT2B, and 5-HT2C), 5-HT3, 5-HT4, 5-HT5 (5-HT5A and 5-HT5B), 5-HT6, and 5-HT7. 5-HT receptor-specific agonists and antagonists have been designed and developed as therapeutics against mental disorders. Among the 5-HT receptors, the most well-studied receptor is 5-HT1A, known as an autoreceptor, which has inhibitory control over the 5-HT neuronal activity. Increased levels of 5-HT1A in 5-HT neurons of the dorsal raphe have been reported in MDD patients and suicide victims with MDD (Stockmeier et al., 1998; Hesselgrave and Parsey, 2013). 5HT1A is also a postsynaptic receptor, expressed in main target brain areas, the hippocampal, cortical, and hypothalamic regions, that are associated with depression, stress, and anxiety (Albert et al., 2019). Several SNPs and stress-induced DNA methylation of the 5-HT1A promoter have been associated with MDD and alteration in their response to antidepressants. $\mathrm{C}(-1,019) \mathrm{G}$ (rs6295) is a functional 5-HT1A promoter polymorphism that modifies $5-H T 1 A$ gene expression in a brain region-specific manner (Le Francois et al., 2008) and modify connectivity such as amygdala-ventrolateral prefrontal cortex, and corticolimbic connectivity related to MDD (Vai et al., 2017). In fact, C $(-1,019) \mathrm{G}$ (rs6295) promoter 
polymorphism in 5-HT1A elevated risk of depression (Benedetti et al., 2011; Kim et al., 2011; Vai et al., 2017), resistance to an antidepressant (Wang et al., 2018b), panic disorder (Choe et al., 2013), fear (Straube et al., 2014), gender-dependent modulatory effects on depression, physical function in patients with pain (Lebe et al., 2013), and suicidal attempt in MDD (Sawiniec et al., 2007). Kim and co-workers have reported interactions between C-1019G polymorphism in 5HT1A and negative life stressors that account for MDD symptoms (Kim et al., 2011). These findings support those genetic alterations of the 5-HT1A promoter that make it sensitive to stress and increase the risk of MDD.

Some studies have suggested that human 5HT1A gene methylation is associated with MDD. Increased DNA methylation of 5HT1A promoter in leukocytes has been reported in bipolar depression (Carrard et al., 2011). Stress-linked hypomethylation of CpG668 site in the 5HT1A gene from blood samples is associated with resistance to antidepressants in treatment-naive MDD patients (Wang et al., 2018a).

Studies in animal models suggest that early-life social stress induces persistent changes in 5-HT1A expression levels in the amygdala, hippocampus, and dorsal raphe nucleus (Bravo et al., 2014). Furthermore, early-life stress, in combination with adult social isolation, dramatically decreases the 5-HT1A-mediated inhibition of layer II/III pyramidal neuronal activities (Goodfellow et al., 2009). Le Francois and co-workers have reported methylation of $24 \mathrm{CpG}$ sites on the mouse 5-HT1A promoter, and chronic mild stress increased DNA methylation of a single site located within the Sp4 element of the 5HT1A gene that correlates with increased mRNA expression levels in the raphe and prefrontal cortex in male mice (Le Francois et al., 2015). In brief, subjects with methylation of the 5-HT1A gene variant may be more susceptible to developing MDD.

Other variants of 5-HT receptors have also been reported to have a risk of MDD. Methylation of 5-HTR2A genotype at two CpG sites $(-1,420$ and $-1,224)$ has been associated with PTSD and MDD under contextual stress (Parade et al., 2017). An SNP in the allele of $-1438 \mathrm{~A} / \mathrm{G}$ (rs6311) in the 5HTR2A promoter is highly influenced by genetic factors and the environment in female MDD patients (Lebe et al., 2013). These studies support that 5HT2A methylation is a mechanism by which early adversity is biologically encoded. In another case, epigenetic modification of the 5-HT3A is involved in the molecular mechanism underlying the relationship between childhood maltreatment and the severity of neuropsychiatric diseases in adulthood (Perroud et al., 2016). These studies of epigenetic regulation of 5-HT and 5-HT receptors could be applied for more effective personalized treatments for MDD.

\section{Brain-Derived Neurotrophic Factor}

Brain-derived neurotrophic factor (BDNF) is a neurotrophin involved in many of the brain's activities, including, but not limited to, neuronal development, synaptic modulation, and plasticity, as well as hippocampal function (McAllister et al., 1999; Huang and Reichardt, 2001; Lu, 2003; Monteggia et al., 2004). While BDNF plays a role in serotonergic expression, it may also itself be regulated by 5-HT, particularly in depression and stress (Martinowich and Lu, 2008). During the depression, the role of BDNF can vary; in the hippocampus and the prefrontal cortex, BDNF expression is associated with inhibition of depressive symptoms, whereas it promotes anxiety-like symptoms in the nucleus accumbens and the amygdala (Yu and Chen, 2011). Higher DNA methylation of the Bdnf gene has been associated with the improved antidepressant response, with escitalopram treatment increasing methylation after 8 weeks (Wang et al., 2018b).

The effect of early life stress on BDNF has been well studied in the past decade. Maltreatment of rat pups by stressed caretakers during infancy elicited significant methylation of $B d n f$ exons in the prefrontal cortex - the presence of methylation persists even into adulthood, demonstrating a long-term effect (Roth et al., 2009). The postnatal maternal separation was found to induce a decrease in exon IV $B d n f$ mRNA, with adult restraint stress further exacerbating the maternal separation-induced drop in BDNF expression (Seo et al., 2016). Furthermore, Bdnf promoter IV displays a decrease in acetylation of histone $3(\mathrm{H} 3)$ and histone $4(\mathrm{H} 4)$ in adult restraint stress, and further reduction in acetylation of $\mathrm{H} 3$ and $\mathrm{H} 4$ is observed from maternal separation. However, these epigenetic changes can be recovered by escitalopram treatment (Seo et al., 2016).

In addition to postnatal maternal separation, which occurs at a very young age, adolescent social stress in mice also causes epigenetic changes to BDNF in adulthood (Xu et al., 2018). Here, Bdnf gene expression is downregulated in the medial prefrontal cortex as a result of adolescent social stress, and increased dimethylation of $\mathrm{H3}$ at lysine 9 (H3K9me2) downstream of the $B d n f$ IV promoter - his occurs in conjunction with cognitive flexibility in the mice after reaching adulthood. Both epigenetic changes and behavioral changes can be reverted by antidepressant treatment (Xu et al., 2018). The effect of maternal separation on behavior has been examined in a similar study; early-life interaction with a stranger can induce a stressful social experience, and as a result, less social interaction with strangers is observed from pups who have been separated from their mothers (Karen and Rajan, 2019). Furthermore, the stressful social experience subsequently elevated DNA methyltransferase (Dnmt3a) as well as other epigenetic elements such as decreased acetylation and increased methylation of histones in the amygdala of rats, which had been raised under maternal separation (Karen and Rajan, 2019).

In addition to stress-induced epigenetic changes, a recent study also investigates the effect of early life stress across generations and gender. By subjecting the first generation of rats to maternal separation and the subsequent generation raised in a balanced cross-fostering manner, it was found that early-life stress through maternal separation resulted in increased $B d n f$ methylation in both male and female rats, but $B d n f$ expression was reduced only in females (Coley et al., 2019). Subsequently, the second-generation rats from an early life social stress lineage exhibited increased $B d n f$ methylation, while fostered female rats raised by a first-generation mother, which had previously undergone early life stress exhibited Bdnf methylation (Coley et al., 2019). 
These studies suggest that stress-induced epigenetic changes are carried across generations.

\section{TREATMENTS ATTENUATING EARLY-LIFE SOCIAL STRESS CHANGES}

While early-life social stress may induce adverse epigenetic and behavioral changes, these changes might not be entirely irreversible. As noted above, the use of antidepressants such as escitalopram has proven effective in recovering epigenetic changes in the Bdnf gene in both humans and rats (Seo et al., 2016; Wang et al., 2018b). Lithium treatment has been noted to reverse the effects of early-life social stress by increasing neuropeptide $\mathrm{Y}$ and corticotropin-releasing hormone - both associated with depression and stress vulnerability - in the adult rat hypothalamus (Husum and Mathé, 2002). Valproic acid treatment helps treat cognitive dysfunction induced by amphetamine to mimic a later-life social stress event. Still, a combination of both early life stress and later life stress renders the treatment ineffective (Pinheiro et al., 2012). Other treatments attenuating early-life social stress changes can be found in corticotropin-releasing hormone blockers, which recover early-life social stress-induced hippocampal dysfunction (Ivy et al., 2010), or the use of dopamine receptor 3 (Drd3) agonists to increase dopaminergic neuronal activity, which has been shown to restore normal social behavior in mice that have undergone early-life social stress (Shin et al., 2018).

\section{LIMITATIONS AND FUTURE PERSPECTIVES}

While the role of epigenetics in regulating 5-HT-associated genes under early-life social stress appears to be backed by substantial evidence, limitations remain when it comes to translating those results to clinical research; after all, the same methods used to directly study the expressions of genes in the rodent brain cannot be effectively implemented with humans. The relative scarcity of neurological data available means that investigation of peripheral expression levels for genes such as 5-HTT (Olsson et al., 2010) and BDNF (Lopez et al., 2013) in association with epigenetic regulation under exposure to early life stress is necessary for future research. Furthermore, future studies may also want to consider and compare the effect of the social and natural environment on epigenetic regulation; stress in early life can come through various means, and as such, natural obstacles such as food deprivation may yet generate different responses compared to social stress.

Even so, epigenetic studies have proven to be highly useful in improving our understanding of the biological processes that serve as the fundament for social influences on health. By combining human epidemiological studies and animal model experimental studies, the role of epigenetic mechanisms in social stress-related health risks should become clearer. This would help advise public health and social interventions, which serve to reduce epigenetic aging and improve longterm health.

\section{SUMMARY}

Early life social stress may be a driving force for susceptibility to depression in later years, and epigenetic regulation of serotonin-associated genes is another means by which early-life social stress exerts its influence (Figure 1). Genetic changes to the associated genes in later life have proven to be a strong indicator for depressive disorders in both animal models and clinical studies - this suggests that targeted recovery of these

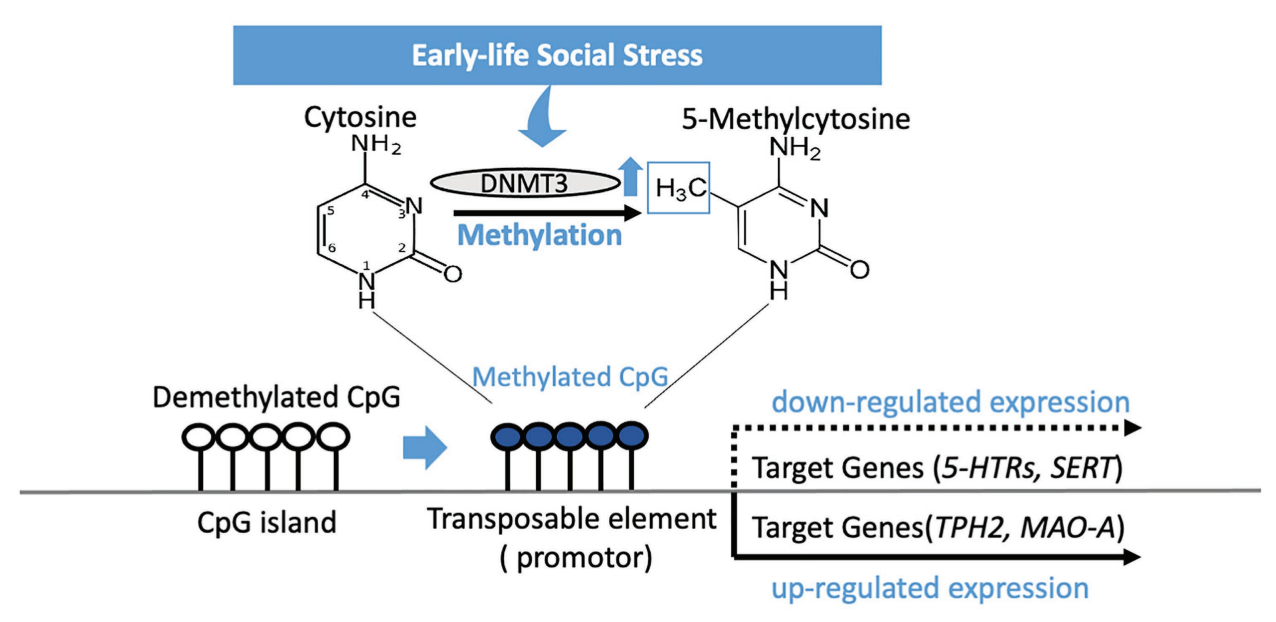

FIGURE 1 I DNA methylation of CpG islands in the genetic code silences expression of a gene after early-life social stress exposure. Methylation occurs by a methyltransferase (DNMT3) transferring a methyl group to cytosine, and when occurring on a transposable element has the effect of repressing gene transcription related to that element. 5-HTRs, 5-HT receptors; SERT, serotonin transporter; TPH2, tryptophan hydroxylase 2; MAO-A, monoamine oxidase A. 
epigenetic changes is a potential path to take when considering treatment of the major depressive disorder. Epigenetic changes to serotonin-associated genes are tied directly to increased or decreased genetic expression, which in turn is correlated to behaviors distinctive of depressive disorders. However, one thing of note when it comes to epigenetic changes in the sexual dimorphism present in their effects is an observation that is recurring in both BDNF and MAOA, where the presence of the epigenetic changes might be opposed or non-existent depending on the sex. Regardless, as progress in epigenetics advances, greater understanding and better treatment philosophies for depression may arise in the future.

\section{REFERENCES}

Abdolmaleky, H. M., Nohesara, S., Ghadirivasfi, M., Lambert, A. W., Ahmadkhaniha, H., Ozturk, S., et al. (2014). DNA hypermethylation of serotonin transporter gene promoter in drug naïve patients with schizophrenia. Schizophr. Res. 152, 373-380. doi: 10.1016/j.schres.2013.12.007

Albert, P. R., Le Francois, B., and Vahid-Ansari, F. (2019). Genetic, epigenetic and posttranscriptional mechanisms for treatment of major depression: the 5-HT1A receptor gene as a paradigm. J. Psychiatry Neurosci. 44, 164-176. doi: 10.1503/jpn.180209

Anguelova, M., Benkelfat, C., and Turecki, G. (2003). A systematic review of association studies investigating genes coding for serotonin receptors and the serotonin transporter: I. affective disorders. Mol. Psychiatry 8, 574-591. doi: $10.1038 /$ s.mp. 4001328

Bendre, M., Granholm, L., Drennan, R., Meyer, A., Yan, L., Nilsson, K. W., et al. (2019). Early life stress and voluntary alcohol consumption in relation to Maoa methylation in male rats. Alcohol 79, 7-16. doi: 10.1016/j. alcohol.2018.11.001

Benedetti, F., Radaelli, D., Poletti, S., Locatelli, C., Dallaspezia, S., Lorenzi, C., et al. (2011). Association of the C(-1019)G 5-HT1A promoter polymorphism with exposure to stressors preceding hospitalization for bipolar depression. J. Affect. Disord. 132, 297-300. doi: 10.1016/j.jad.2011.02.024

Bravo, J. A., Dinan, T. G., and Cryan, J. F. (2014). Early-life stress induces persistent alterations in 5-HT1A receptor and serotonin transporter mRNA expression in the adult rat brain. Front. Mol. Neurosci. 7:24. doi: 10.3389/ fnmol.2014.00024

Bunea, I. M., Szentágotai-Tătar, A., and Miu, A. C. (2017). Early-life adversity and cortisol response to social stress: a meta-analysis. Transl. Psychiatry 7:1274. doi: 10.1038/s41398-017-0032-3

Carini, L. M., and Nephew, B. C. (2013). Effects of early life social stress on endocrinology, maternal behavior, and lactation in rats. Horm. Behav. 64, 634-641. doi: 10.1016/j.yhbeh.2013.08.011

Carrard, A., Salzmann, A., Malafosse, A., and Karege, F. (2011). Increased DNA methylation status of the serotonin receptor 5HTR1A gene promoter in schizophrenia and bipolar disorder. J. Affect. Disord. 132, 450-453. doi: 10.1016/j.jad.2011.03.018

Caspi, A., Sugden, K., Moffitt, T. E., Taylor, A., Craig, I. W., Harrington, H., et al. (2003). Influence of life stress on depression: moderation by a polymorphism in the 5-HTT gene. Science 301:386. doi: 10.1126/science.1083968

Chen, Y. -W., Lin, P. -Y., Tu, K. -Y., Cheng, Y. -S., Wu, C. -K., and Tseng, P. -T. (2015). Significantly lower nerve growth factor levels in patients with major depressive disorder than in healthy subjects: a meta-analysis and systematic review. Neuropsychiatr. Dis. Treat. 11, 925-933. doi: 10.2147/NDT.S81432

Chen, G. L., and Miller, G. M. (2012). Advances in tryptophan hydroxylase-2 gene expression regulation: new insights into serotonin-stress interaction and clinical implications. Am. J. Med. Genet. B Neuropsychiatr. Genet. 159B, 152-171. doi: 10.1002/ajmg.b.32023

Choe, A. Y., Kim, B., Lee, K. S., Lee, J. E., Lee, J. Y., Choi, T. K., et al. (2013). Serotonergic genes (5-HTT and HTR1A) and separation life events: gene-by-environment interaction for panic disorder. Neuropsychobiology 67, 192-200. doi: $10.1159 / 000347084$

\section{AUTHOR CONTRIBUTIONS}

TS and IP designed the flow of this review paper and edited the manuscript. TS and CT wrote the main manuscript and prepared a figure. All authors contributed to the article and approved the submitted version.

\section{FUNDING}

This work was supported by research grant from Monash University Malaysia.

Coley, E. J. L., Demaestri, C., Ganguly, P., Honeycutt, J. A., Peterzell, S., Rose, N., et al. (2019). Cross-Generational transmission of early life stress effects on HPA regulators and Bdnf are mediated by sex, lineage, and upbringing. Front. Behav. Neurosci. 13:101. doi: 10.3389/fnbeh.2019.00101

Crabtree, J. S. (ed.) (2020). "Chapter 3 - fundamentals of epigenetics" in Clinical Precision Medicine (Cambridge, Massachusetts, USA: Academic Press), 27-37.

Denhardt, D. T. (2018). Effect of stress on human biology: epigenetics, adaptation, inheritance, and social significance. J. Cell. Physiol. 233, 1975-1984. doi: $10.1002 /$ jcp. 25837

Domschke, K., Tidow, N., Schwarte, K., Ziegler, C., Lesch, K. -P., Deckert, J., et al. (2015). Pharmacoepigenetics of depression: no major influence of MAO-A DNA methylation on treatment response. J. Neural Transm. 122, 99-108. doi: 10.1007/s00702-014-1227-x

Eiland, L., and McEwen, B. S. (2012). Early life stress followed by subsequent adult chronic stress potentiates anxiety and blunts hippocampal structural remodeling. Hippocampus 22, 82-91. doi: 10.1002/hipo.20862

Enoch, M. A., Steer, C. D., Newman, T. K., Gibson, N., and Goldman, D. (2010). Early life stress, MAOA, and gene-environment interactions predict behavioral disinhibition in children. Genes Brain Behav. 9, 65-74. doi: 10.1111/j.1601-183X.2009.00535.X

Fogelman, N., and Canli, T. (2019). Early life stress, physiology, and genetics: a review. Front. Psychol. 10:1668. doi: 10.3389/fpsyg.2019.01668

Gao, J., Pan, Z., Jiao, Z., Li, F., Zhao, G., Wei, Q., et al. (2012). TPH2 gene polymorphisms and major depression--a meta-analysis. PLoS One 7:e36721. doi: 10.1371/journal.pone.0036721

Goodfellow, N. M., Benekareddy, M., Vaidya, V. A., and Lambe, E. K. (2009). Layer II/III of the prefrontal cortex: inhibition by the serotonin 5-HT1A receptor in development and stress. J. Neurosci. 29, 10094-10103. doi: 10.1523/ JNEUROSCI.1960-09.2009

Gudsnuk, K., and Champagne, F. A. (2012). Epigenetic influence of stress and the social environment. ILAR J. 53, 279-288. doi: 10.1093/ilar.53.3-4.279

Hahn, M. K., and Blakely, R. D. (2002). Monoamine transporter gene structure and polymorphisms in relation to psychiatric and other complex disorders. Pharm. J. 2, 217-235. doi: 10.1038/sj.tpj.6500106

Harlow, H. F., and Suomi, S. J. (1974). Induced depression in monkeys. Behav. Biol. 12, 273-296. doi: 10.1016/s0091-6773(74)91475-8

Heim, C., and Binder, E. B. (2012). Current research trends in early life stress and depression: review of human studies on sensitive periods, gene-environment interactions, and epigenetics. Exp. Neurol. 233, 102-111. doi: 10.1016/j. expneurol.2011.10.032

Hesselgrave, N., and Parsey, R. V. (2013). Imaging the serotonin 1A receptor using [11C]WAY100635 in healthy controls and major depression. Philos Trans. R. Soc. Lond. Ser. B Biol. Sci. 368:20120004. doi: 10.1098/rstb.2012.0004

Hettema, J. M., Kuhn, J. W., Prescott, C. A., and Kendler, K. S. (2006). The impact of generalized anxiety disorder and stressful life events on risk for major depressive episodes. Psychol. Med. 36, 789-795. doi: 10.1017/ S0033291706007367

Hochberg, Z. e., Feil, R., Constancia, M., Fraga, M., Junien, C., Carel, J. -C., et al. (2011). Child health, developmental plasticity, and epigenetic programming. Endocr. Rev. 32, 159-224. doi: 10.1210/er.2009-0039

Houwing, D. J., Ramsteijn, A. S., Riemersma, I. W., and Olivier, J. D. A. (2019). Maternal separation induces anhedonia in female heterozygous 
serotonin transporter knockout rats. Behav. Brain Res. 356, 204-207. doi: 10.1016/j.bbr.2018.08.031

Huang, L. -T. (2014). Early-life stress impacts the developing hippocampus and primes seizure occurrence: cellular, molecular, and epigenetic mechanisms. Front. Mol. Neurosci. 7:8. doi: 10.3389/fnmol.2014.00008

Huang, E. J., and Reichardt, L. F. (2001). Neurotrophins: roles in neuronal development and function. Annu. Rev. Neurosci. 24, 677-736. doi: 10.1146/ annurev.neuro.24.1.677

Husum, H., and Mathé, A. A. (2002). Early life stress changes concentrations of neuropeptide $\mathrm{Y}$ and Corticotropin-releasing hormone in adult rat brain. Lithium treatment modifies these changes. Neuropsychopharmacology 27, 756-764. doi: 10.1016/S0893-133X(02)00363-9

Inoue, H., Yamasue, H., Tochigi, M., Takei, K., Suga, M., Abe, O., et al. (2010). Effect of tryptophan hydroxylase-2 gene variants on amygdalar and hippocampal volumes. Brain Res. 1331, 51-57. doi: 10.1016/j.brainres.2010 .03 .057

Ivy, A. S., Rex, C. S., Chen, Y., Dubé, C., Maras, P. M., Grigoriadis, D. E., et al. (2010). Hippocampal dysfunction and cognitive impairments provoked by chronic early-life stress involve excessive activation of $\mathrm{CRH}$ receptors. J. Neurosci. 30:13005. doi: 10.1523/JNEUROSCI.1784-10.2010

Jiang, S., Postovit, L., Cattaneo, A., Binder, E. B., and Aitchison, K. J. (2019). Epigenetic modifications in stress response genes associated with childhood trauma. Front. Psych. 10:808. doi: 10.3389/fpsyt.2019.00808

Kanner, B. I., and Schuldiner, S. (1987). Mechanism of transport and storage of neurotransmitters. CRC Crit. Rev. Biochem. 22, 1-38. doi: 10.3109/ 10409238709082546

Karen, C., and Rajan, K. E. (2019). Social behaviour and epigenetic status in adolescent and adult rats: the contribution of early-life stressful social experience. Cell. Mol. Neurobiol. 39, 371-385. doi: 10.1007/s10571-01900655-x

Kim, H. K., Kim, S. J., Lee, Y. J., Lee, H. J., Kang, S. G., Choi, J. E., et al. (2011). Influence of the interaction between the serotonin $1 \mathrm{~A}$ receptor C-1019G polymorphism and negative life stressors on the development of depression. Neuropsychobiology 64, 1-8. doi: 10.1159/000322144

Konar, A., Rastogi, M., and Bhambri, A. (2019). Brain region specific methylation and Sirtl binding changes in MAOA promoter is associated with sexual dimorphism in early life stress induced aggressive behavior. Neurochem. Int. 129:104510. doi: 10.1016/j.neuint.2019.104510

Labonté, B., Suderman, M., Maussion, G., Navaro, L., Yerko, V., Mahar, I., et al. (2012). Genome-wide epigenetic regulation by early-life trauma. Arch. Gen. Psychiatry 69, 722-731. doi: 10.1001/archgenpsychiatry.2011.2287

Lam, D., Ancelin, M. -L., Ritchie, K., Freak-Poli, R., Saffery, R., and Ryan, J. (2018). Genotype-dependent associations between serotonin transporter gene (SLC6A4) DNA methylation and late-life depression. BMC Psychiatry 18:282. doi: 10.1186/s12888-018-1850-4

Lapp, H. E., Ahmed, S., Moore, C. L., and Hunter, R. G. (2019). Toxic stress history and hypothalamic-pituitary-adrenal axis function in a social stress task: genetic and epigenetic factors. Neurotoxicol. Teratol. 71, 41-49. doi: 10.1016/j.ntt.2018.01.011

Le Francois, B., Czesak, M., Steubl, D., and Albert, P. R. (2008). Transcriptional regulation at a HTR1A polymorphism associated with mental illness. Neuropharmacology 55, 977-985. doi: 10.1016/j.neuropharm.2008.06.046

Le Francois, B., Soo, J., Millar, A. M., Daigle, M., Le Guisquet, A. M., Leman, S., et al. (2015). Chronic mild stress and antidepressant treatment alter 5-HT1A receptor expression by modifying DNA methylation of a conserved Sp4 site. Neurobiol. Dis. 82, 332-341. doi: 10.1016/j.nbd.2015.07.002

Lebe, M., Hasenbring, M. I., Schmieder, K., Jetschke, K., Harders, A., Epplen, J. T., et al. (2013). Association of serotonin-1A and $-2 \mathrm{~A}$ receptor promoter polymorphisms with depressive symptoms, functional recovery, and pain in patients 6 months after lumbar disc surgery. Pain 154, 377-384. doi: 10.1016/j.pain.2012.11.017

Lesch, K. P., Balling, U., Gross, J., Strauss, K., Wolozin, B. L., Murphy, D. L., et al. (1994). Organization of the human serotonin transporter gene. J. Neural Transm. Gen. Sect. 95, 157-162. doi: 10.1007/BF01276434

Lindell, S. G., Yuan, Q., Zhou, Z., Goldman, D., Thompson, R. C., Lopez, J. F., et al. (2012). The serotonin transporter gene is a substrate for age and stress dependent epigenetic regulation in rhesus macaque brain: potential roles in genetic selection and gene $\times$ environment interactions. Dev. Psychopathol. 24, 1391-1400. doi: 10.1017/S0954579412000788
Lopez, J. P., Mamdani, F., Labonte, B., Beaulieu, M. M., Yang, J. P., Berlim, M. T., et al. (2013). Epigenetic regulation of BDNF expression according to antidepressant response. Mol. Psychiatry 18, 398-399. doi: 10.1038/mp.2012.38 Lu, B. (2003). BDNF and activity-dependent synaptic modulation. Learn. Mem. 10, 86-98. doi: 10.1101/lm.54603

Mann, J. J., Huang, Y. Y., Underwood, M. D., Kassir, S. A., Oppenheim, S., Kelly, T. M., et al. (2000). A serotonin transporter gene promoter polymorphism (5-HTTLPR) and prefrontal cortical binding in major depression and suicide. Arch. Gen. Psychiatry 57, 729-738. doi: 10.1001/archpsyc.57.8.729

Márquez, C., Poirier, G. L., Cordero, M. I., Larsen, M. H., Groner, A., Marquis, J., et al. (2013). Peripuberty stress leads to abnormal aggression, altered amygdala and orbitofrontal reactivity and increased prefrontal MAOA gene expression. Transl. Psychiatry 3, e216-e216. doi: 10.1038/tp.2012.144

Martinowich, K., and Lu, B. (2008). Interaction between BDNF and serotonin: role in mood disorders. Neuropsychopharmacology 33, 73-83. doi: 10.1038/ sj.npp. 1301571

McAllister, A. K., Katz, L. C., and Lo, D. C. (1999). Neurotrophins and synaptic plasticity. Annu. Rev. Neurosci. 22, 295-318.

McCann, K. E., Rosenhauer, A. M., Jones, G. M. F., Norvelle, A., Choi, D. C., and Huhman, K. L. (2017). Histone deacetylase and acetyltransferase inhibitors modulate behavioral responses to social stress. Psychoneuroendocrinology 75 , 100-109. doi: 10.1016/j.psyneuen.2016.10.022

McClelland, S., Korosi, A., Cope, J., Ivy, A., and Baram, T. Z. (2011). Emerging roles of epigenetic mechanisms in the enduring effects of early-life stress and experience on learning and memory. Neurobiol. Learn. Mem. 96, 79-88. doi: 10.1016/j.nlm.2011.02.008

Melas, P. A., Wei, Y., Wong, C. C. Y., Sjöholm, L. K., Åberg, E., Mill, J., et al. (2013). Genetic and epigenetic associations of MAOA and NR3C1 with depression and childhood adversities. Int. J. Neuropsychopharmacol. 16, 1513-1528. doi: 10.1017/S1461145713000102

Monteggia, L. M., Barrot, M., Powell, C. M., Berton, O., Galanis, V., Gemelli, T., et al. (2004). Essential role of brain-derived neurotrophic factor in adult hippocampal function. Proc. Natl. Acad. Sci. 101, 10827-10832. doi: 10.1073/ pnas.0402141101

Murgatroyd, C., Patchev, A. V., Wu, Y., Micale, V., Bockmühl, Y., Fischer, D., et al. (2009). Dynamic DNA methylation programs persistent adverse effects of early-life stress. Nat. Neurosci. 12, 1559-1566. doi: 10.1038/nn.2436

Murgatroyd, C. A., Peña, C. J., Podda, G., Nestler, E. J., and Nephew, B. C. (2015). Early life social stress induced changes in depression and anxiety associated neural pathways which are correlated with impaired maternal care. Neuropeptides 52, 103-111. doi: 10.1016/j.npep.2015.05.002

Murphy, D. L., Lerner, A., Rudnick, G., and Lesch, K. -P. (2004). Serotonin transporter: gene, genetic disorders, and pharmacogenetics. Mol. Interv. 4:109. doi: $10.1124 / \mathrm{mi} .4 .2 .8$

Naoi, M., Maruyama, W., and Shamoto-Nagai, M. (2018). Type A monoamine oxidase and serotonin are coordinately involved in depressive disorders: from neurotransmitter imbalance to impaired neurogenesis. J. Neural Transm. 125, 53-66. doi: 10.1007/s00702-017-1709-8

Nikolova, Y. S., Koenen, K. C., Galea, S., Wang, C. -M., Seney, M. L., Sibille, E., et al. (2014). Beyond genotype: serotonin transporter epigenetic modification predicts human brain function. Nat. Neurosci. 17, 1153-1155. doi: 10.1038/ nn. 3778

Nugent, N. R., Tyrka, A. R., Carpenter, L. L., and Price, L. H. (2011). Geneenvironment interactions: early life stress and risk for depressive and anxiety disorders. Psychopharmacology 214, 175-196. doi: 10.1007/s00213-010-2151-x

Oberlander, T. F., Weinberg, J., Papsdorf, M., Grunau, R., Misri, S., and Devlin, A. M. (2008). Prenatal exposure to maternal depression, neonatal methylation of human glucocorticoid receptor gene (NR3C1) and infant cortisol stress responses. Epigenetics 3, 97-106. doi: 10.4161/epi.3.2.6034

Olsson, C. A., Foley, D. L., Parkinson-Bates, M., Byrnes, G., McKenzie, M., Patton, G. C., et al. (2010). Prospects for epigenetic research within cohort studies of psychological disorder: a pilot investigation of a peripheral cell marker of epigenetic risk for depression. Biol. Psychol. 83, 159-165. doi: 10.1016/j.biopsycho.2009.12.003

Ouellet-Morin, I., Wong, C. C. Y., Danese, A., Pariante, C. M., Papadopoulos, A. S., Mill, J., et al. (2013). Increased serotonin transporter gene (SERT) DNA methylation is associated with bullying victimization and blunted cortisol response to stress in childhood: a longitudinal study of discordant monozygotic twins. Psychol. Med. 43, 1813-1823. doi: 10.1017/S0033291712002784 
Pace, T. W. W., Mletzko, T. C., Alagbe, O., Musselman, D. L., Nemeroff, C. B., Miller, A. H., et al. (2006). Increased stress-induced inflammatory responses in male patients with major depression and increased early life stress. Am. J. Psychiatr. 163, 1630-1633. doi: 10.1176/ajp.2006.163.9.1630

Parade, S. H., Novick, A. M., Parent, J., Seifer, R., Klaver, S. J., Marsit, C. J., et al. (2017). Stress exposure and psychopathology alter methylation of the serotonin receptor 2A (HTR2A) gene in preschoolers. Dev. Psychopathol. 29, 1619-1626. doi: 10.1017/S0954579417001274

Perroud, N., Zewdie, S., Stenz, L., Adouan, W., Bavamian, S., Prada, P., et al. (2016). Methylation of serotonin receptor 3a in Adhd, borderline personality, and bipolar disorders: link with severity of the disorders and childhood maltreatment. Depress. Anxiety 33, 45-55. doi: 10.1002/da.22406

Pinheiro, R. M. C., de Lima, M. N. M., Fries, G. R., Garcia, V. A., Presti-Torres, J., Hallmenschlager, L. H., et al. (2012). Early life stress exacerbates cognitive dysfunction induced by d-amphetamine: amelioration by valproic acid. $J$. Neural Transm. 119, 627-637. doi: 10.1007/s00702-011-0754-y

Provençal, N., and Binder, E. B. (2015). The effects of early life stress on the epigenome: from the womb to adulthood and even before. Exp. Neurol. 268, 10-20. doi: 10.1016/j.expneurol.2014.09.001

Rao, U., Hammen, C., Ortiz, L. R., Chen, L. -A., and Poland, R. E. (2008). Effects of early and recent adverse experiences on adrenal response to psychosocial stress in depressed adolescents. Biol. Psychiatry 64, 521-526. doi: 10.1016/j.biopsych.2008.05.012

Roth, T. L., Lubin, F. D., Funk, A. J., and Sweatt, J. D. (2009). Lasting epigenetic influence of early-life adversity on the BDNF gene. Biol. Psychiatry 65, 760-769. doi: 10.1016/j.biopsych.2008.11.028

Ryabinin, A. E., Tsoory, M. M., Kozicz, T., Thiele, T. E., Neufeld-Cohen, A., Chen, A., et al. (2012). Urocortins: CRF's siblings and their potential role in anxiety, depression and alcohol drinking behavior. Alcohol 46, 349-357. doi: 10.1016/j.alcohol.2011.10.007

Sawiniec, J., Borkowski, K., Ginalska, G., and Lewandowska-Stanek, H. (2007). Association between 5-hydroxytryptamine $1 \mathrm{~A}$ receptor gene polymorphism and suicidal behavior. Przegl. Lek. 64, 208-211.

Schneider, I., Kugel, H., Redlich, R., Grotegerd, D., Bürger, C., Bürkner, P. -C., et al. (2018). Association of Serotonin transporter gene AluJb methylation with major depression, amygdala responsiveness, 5-HTTLPR/rs25531 polymorphism, and stress. Neuropsychopharmacology 43, 1308-1316. doi: 10.1038/npp.2017.273

Schoenherr, C. J., and Anderson, D. J. (1995). The neuron-restrictive silencer factor (NRSF): a coordinate repressor of multiple neuron-specific genes. Science 267, 1360-1363. doi: 10.1126/science.7871435

Seo, M. K., Ly, N. N., Lee, C. H., Cho, H. Y., Choi, C. M., Nhu, L. H., et al. (2016). Early life stress increases stress vulnerability through BDNF gene epigenetic changes in the rat hippocampus. Neuropharmacology 105, 388-397. doi: 10.1016/j.neuropharm.2016.02.009

Shen, T., Li, X., Chen, L., Chen, Z., Tan, T., Hua, T., et al. (2020). The relationship of tryptophan hydroxylase-2 methylation to early-life stress and its impact on short-term antidepressant treatment response. J. Affect. Disord. 276, 850-858. doi: 10.1016/j.jad.2020.07.111

Shin, S., Pribiag, H., Lilascharoen, V., Knowland, D., Wang, X. -Y., and Lim, B. K. (2018). Drd3 signaling in the lateral septum mediates early life stress-induced social dysfunction. Neuron 97, 195-208.e196. doi: 10.1016/j.neuron.2017.11.040

Shumay, E., Logan, J., Volkow, N. D., and Fowler, J. S. (2012). Evidence that the methylation state of the monoamine oxidase a (MAOA) gene predicts brain activity of MAO a enzyme in healthy men. Epigenetics 7, 1151-1160. doi: $10.4161 /$ epi.21976

Stockmeier, C. A., Shapiro, L. A., Dilley, G. E., Kolli, T. N., Friedman, L., and Rajkowska, G. (1998). Increase in serotonin-1A autoreceptors in the midbrain of suicide victims with major depression-postmortem evidence for decreased serotonin activity. J. Neurosci. 18, 7394-7401.

Straube, B., Reif, A., Richter, J., Lueken, U., Weber, H., Arolt, V., et al. (2014). The functional-1019C/G HTR1A polymorphism and mechanisms of fear. Transl. Psychiatry 4:e490. doi: 10.1038/tp.2014.130

Suomi, S. J., Collins, M. L., Harlow, H. F., and Ruppenthal, G. C. (1976). Effects of maternal and peer separations on young monkeys. J. Child Psychol. Psychiatry 17, 101-112. doi: 10.1111/j.1469-7610.1976.tb00382.x

Tsai, S. J., Hong, C. J., Liou, Y. J., Yu, Y. W., Chen, T. J., Hou, S. J., et al. (2009). Tryptophan hydroxylase 2 gene is associated with major depression and antidepressant treatment response. Prog. Neuro-Psychopharmacol. Biol. Psychiatry 33, 637-641. doi: 10.1016/j.pnpbp.2009.02.020

Vai, B., Riberto, M., Ghiglino, D., Poletti, S., Bollettini, I., Lorenzi, C., et al. (2017). A 5-HT1Areceptor promoter polymorphism influences fronto-limbic functional connectivity and depression severity in bipolar disorder. Psychiatry Res. Neuroimaging 270, 1-7. doi: 10.1016/j.pscychresns.2017.09.012

Vaiserman, A. M. (2015). Epigenetic programming by early-life stress: evidence from human populations. Dev. Dyn. 244, 254-265. doi: 10.1002/dvdy.24211

van der Doelen, R. H. A., Robroch, B., Arnoldussen, I. A., Schulpen, M., Homberg, J. R., and Kozicz, T. (2017). Serotonin and urocortin 1 in the dorsal raphe and Edinger-Westphal nuclei after early life stress in serotonin transporter knockout rats. Neuroscience, 340, 345-358. doi: 10.1016/j. neuroscience.2016.10.072

Wang, P., Lv, Q., Mao, Y., Zhang, C., Bao, C., Sun, H., et al. (2018a). HTR1A/1B DNA methylation may predict escitalopram treatment response in depressed Chinese Han patients. J. Affect. Disord. 228, 222-228. doi: 10.1016/j. jad.2017.12.010

Wang, P., Zhang, C., Lv, Q., Bao, C., Sun, H., Ma, G., et al. (2018b). Association of DNA methylation in BDNF with escitalopram treatment response in depressed Chinese Han patients. Eur. J. Clin. Pharmacol. 74, 1011-1020. doi: 10.1007/s00228-018-2463-z

Waters, R. P., Rivalan, M., Bangasser, D. A., Deussing, J. M., Ising, M., Wood, S. K., et al. (2015). Evidence for the role of corticotropin-releasing factor in major depressive disorder. Neurosci. Biobehav. Rev. 58, 63-78. doi: 10.1016/j. neubiorev.2015.07.011

Xu, Z., Reynolds, G. P., Yuan, Y., Shi, Y., Pu, M., and Zhang, Z. (2016). TPH-2 polymorphisms interact with early life stress to influence response to treatment with antidepressant drugs. Int. J. Neuropsychopharmacol. 19:pyw070. doi: 10.1093/ijnp/pyw070

Xu, H., Wang, J., Zhang, K., Zhao, M., Ellenbroek, B., Shao, F., et al. (2018). Effects of adolescent social stress and antidepressant treatment on cognitive inflexibility and Bdnf epigenetic modifications in the mPFC of adult mice. Psychoneuroendocrinology 88, 92-101. doi: 10.1016/j.psyneuen.2017.11.013

Xu, Z., Zhang, Z., Shi, Y., Pu, M., Yuan, Y., Zhang, X., et al. (2012). Influence and interaction of genetic polymorphisms in the serotonin system and life stress on antidepressant drug response. J. Psychopharmacol. 26, 349-359. doi: $10.1177 / 0269881111414452$

Yu, H., and Chen, Z. -Y. (2011). The role of BDNF in depression on the basis of its location in the neural circuitry. Acta Pharmacol. Sin. 32, 3-11. doi: 10.1038/aps.2010.184

Zanardi, R., Benedetti, F., Di Bella, D., Catalano, M., and Smeraldi, E. (2000). Efficacy of paroxetine in depression is influenced by a functional polymorphism within the promoter of the serotonin transporter gene. J. Clin. Psychopharmacol. 20, 105-107. doi: 10.1097/00004714-200002000-00021

Zhang, Y., Chang, Z., Chen, J., Ling, Y., Liu, X., Feng, Z., et al. (2015). Methylation of the tryptophan hydroxylase 2 gene is associated with mRNA expression in patients with major depression with suicide attempts. Mol. Med. Rep. 12, 3184-3190. doi: 10.3892/mmr.2015.3748

Zhang, X., Gainetdinov, R. R., Beaulieu, J. M., Sotnikova, T. D., Burch, L. H., Williams, R. B., et al. (2005). Loss-of-function mutation in tryptophan hydroxylase-2 identified in unipolar major depression. Neuron 45, 11-16. doi: 10.1016/j.neuron.2004.12.014

Zill, P., Baghai, T. C., Zwanzger, P., Schule, C., Eser, D., Rupprecht, R., et al. (2004). SNP and haplotype analysis of a novel tryptophan hydroxylase isoform (TPH2) gene provide evidence for association with major depression. Mol. Psychiatry 9, 1030-1036. doi: 10.1038/sj.mp.4001525

Conflict of Interest: The authors declare that the research was conducted in the absence of any commercial or financial relationships that could be construed as a potential conflict of interest.

Copyright (C) 2021 Soga, Teo and Parhar. This is an open-access article distributed under the terms of the Creative Commons Attribution License (CC BY). The use, distribution or reproduction in other forums is permitted, provided the original author(s) and the copyright owner(s) are credited and that the original publication in this journal is cited, in accordance with accepted academic practice. No use, distribution or reproduction is permitted which does not comply with these terms. 